\title{
Learning through play in Grade R classrooms: Measuring practitioners' confidence, knowledge and practice
}

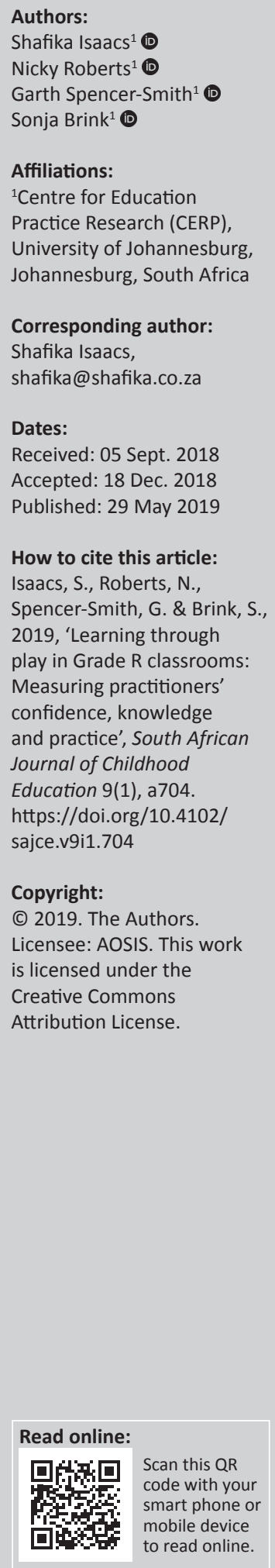

Background: This article reports on the evaluation of a professional development programme for underqualified Grade R practitioners, many of whom work under challenging conditions.

Aim: The study aimed to evaluate the practitioners' confidence, knowledge and practice of play.

Setting: The programme involved a 5-week training programme for 1000 Grade R practitioners across three Eastern Cape districts.

Methods: The study included three data sources: (1) self-reported shifts in confidence and practice solicited through closed Likert-type questions, (2) responses to open-ended questions on knowledge of play and (3) lesson observations of case study practitioners, using a lesson observation protocol to distil quantitative shifts in the practice of case study practitioners $(n=10)$, compared with control practitioners $(n=4)$.

Results: The evaluation found positive shifts in practitioners' self-reporting on their confidence and knowledge of play. However, evidence of their knowledge of play was mixed. Practitioners offered very general conceptions of play, with specific attention on the expected 'form' of play. The use of materials for play, and changed classroom practice from whole class to small groups, were most strongly evident. Because it was short course of 5 weeks, lesson observations of case study practitioners were less positive, with no significant difference between treatment and control lesson observations.

Conclusion: The study opens a window into the implementation of the 5-week professional development programme and the instrumentation used to reflect on practitioners' confidence, knowledge and practice of play. The discussion reflects critically on improving the instrumentation in future for measuring shifts in practitioner confidence, knowledge and practice of play.

Keywords: Grade R; play; play pedagogy; ECD; ECD practitioners; learning through play; teaching through play; professional development.

\section{Introduction}

With the inclusion of Grade R into primary schools in South Africa, we now have the relatively unusual situation where unqualified teachers, who are often student teachers and referred to as 'practitioners,' ${ }^{1}$ are often solely responsible for large classes ${ }^{2}$ of 5-6-year-olds. Under these circumstances, how can Grade R practitioners become qualified Early Childhood Development (ECD) educators? How can their confidence, knowledge and practice of teaching through play be supported?

Learning through play enhances the disposition of children to learn, and enables their content knowledge and their cognitive, social, emotional and physical development. This has been well established, albeit widely contested, in scholarly literature for more than 100 years. Play scholarship has also been growing in recent years, particularly in the Science of Learning field, where new knowledge vistas are opening up with reference to neuroscience and digital play (Brooker, Blaise \& Edwards 2014).

\footnotetext{
1.We use the term 'practitioner' to denote those who are not yet qualified as ECD educators and the term "educator" to refer to those who have a minimum of the National Qualifications Framework Level 4 qualification.

2.'Large classes' refers to class groups of 60-90 children.
} 
However, central to the successful development of cognitive, social and emotional competence in children through play is the role of ECD educators and their skills in integrating playbased pedagogies in their daily practice (Edwards 2017; Neha \& Rule 2018). The extent and nature of ECD educator competencies in play-based pedagogies are inextricably tied to the systemic context within which the public provisioning of ECD services are located, particularly in disadvantaged, resource-challenged communities. However, as argued by Wood (2009), while there is substantial evidence on learning through play, where children are the focus, there is far less evidence on teaching through play (Wood 2009:27).

The South African Government has made various policy commitments since 1994 to promote the right of all children to play, which is underscored by a web of supportive ECD ${ }^{3}$ policies in education, health, welfare and infrastructure (Talbot \& Thornton 2017). A comprehensive review of successes and challenges faced by the ECD sector in South Africa between 1994 and 2011 highlights significant achievements (Atmore 2013; Atmore, Niekerk \& AshleyCooper 2012). Notable, among others, are the establishment of Grade $\mathrm{R}$ as a preschool reception year programme that forms part of primary schooling for children aged 5 years ${ }^{4}$; the availability of ECD subsidies for ECD sites and Grade R grants-in-aid across all nine provinces; and the availability of child support grants for 10.5 million children in 2011. The latter rose to 12 million children in 2017 (Hall 2017). Together, these provide an enabling context for the integration of play in South Africa's ECD curriculum, educator development and assessment.

However, existing policy does not make explicit the conceptual and operational frameworks on teaching through play, play curriculum, and educator professional development and practice of play. The focus of existing policy is more on the availability of play resources and infrastructure, developing safe play spaces, and facilitating parent education and capacity-development programmes on the importance of play (A Chance to Play Southern Africa 2017).

Moreover, in practice, existing literature confirms that ECD educators and practitioners do not have access to adequate training on play-based pedagogies and have limited knowledge and understanding of learning through play as a concept. Many are also not aware of strategies to integrate play-based learning in their classrooms. This is also an area that is significantly understudied, both in South Africa (Aronstam \& Braund 2016; Neha \& Rule 2018) and globally (Ryan \& Northey-Berg 2014; Wood 2009).

In an attempt to contribute to new knowledge on the professional development and practice of ECD practitioners

3.Department of Education 2001:7, refers to ECD as a comprehensive approach to policies and programmes for children from birth to 9 years with active participation of policies and programmes for children from birth to 9 years with active participation of practitioners, their parents and other caregivers' and ECD is referred to as 'the process of emotional, cognitive, sensory, spiritual, moral, physical, social and comr
development from birth to school-going age' (Chapter 6: Section 91:1).

4.Grade $R$ is a single-year preschool programme intended for children in the year before entering Grade 1, implemented in primary schools or community-based ECD sites. on learning and teaching through play, this article analyses the evaluation of findings of a play-based capacity-building programme called 'Play Well and Be Happy' (Play Well \& Be Happy). Established by a partnership between the LEGO ${ }^{\circledR}$ Foundation, Sesame Workshop (and their South African counterpart Takalani Sesame), the Eastern Cape Department of Education and the Buffalo City Metropolitan Municipality (BCMM), Play Well \& Be Happy involved an estimated 1000 Grade $\mathrm{R}$ practitioners in a 5-week training programme that spanned urban and rural settings in one of South Africa's most educationally challenged provinces, the Eastern Cape. Our focus in this article is our attempts at measuring shifts in the confidence, knowledge and practice of ECD practitioners in relation to learning and teaching through play, before and after the Play Well \& Be Happy intervention.

\section{Theoretical foundations}

There is growing attention in global scholarship on playbased pedagogies. The most recent literature acknowledges how the idea of play among humans has emerged since Plato introduced the concept in $643 \mathrm{BC}$ and that today the concept remains nebulous and complex (Brooker et al. 2014). Expanding on Brooker et al. (2014), whose volume on play and learning in early childhood provides a historical overview of the theoretical, conceptual and operational underpinnings of learning through play, Dowker et al. (2018) have shown how differences in the conceptualisation of play have led to definitional confusion. These range from the theoretical debates on play and learning between Vygotsky's (1967) demonstration that sociodramatic play enhances cognitive and social development based on their zone of proximal development in a given play situation to Piaget's (1962) view that children assimilate the external world through play. These debates also include disagreements based on whether play is viewed as that which has no purpose or goal; whether the child initiates and directs play; whether and how caring adults are engaged in activities to scaffold playful learning; whether the play activity is reflective of or separate from real life; and whether it is consistently joyful and stress-free.

In their attempt at providing a widely shared conceptual and operational definition, Zosh et al. (2018) propose that learning through play should be viewed as a spectrum ranging from free play at one end to directed instruction at the other. The criteria applied to categorise the nature of play across this spectrum is informed by whether the play activity has a clearly established goal; and whether it is initiated or directed by the child or by the adult educator or caregiver. For Zosh et al. (2018), free play at the one end of the spectrum draws on definitions supplied by Pellegrini (2009, 2010, 2012) and Weisberg et al. (2013), where play activity is voluntary, without a clear goal or purpose and initiated and directed by the child. This compares with guided play that is directed by the child with the guiding support of adults, whether they are parents, caregivers or educators. This model is demonstrated in Figure 1. 


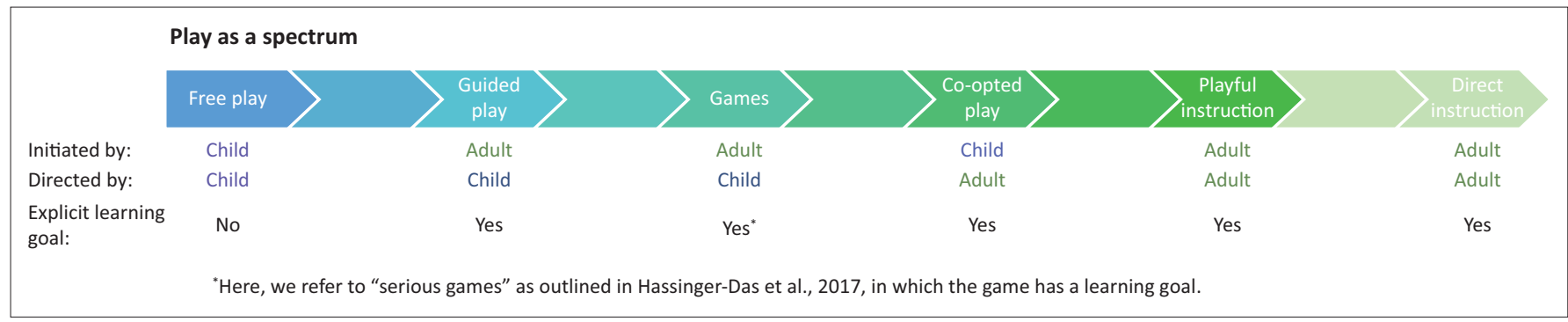

Source: Zosh, J.M., Hirsh-Pasek, K., Hopkins, E.J., Jensen, H., Liu, C.C., Neal, D. et al., 2018, 'Accessing the inaccessible: Redefining play as a spectrum', Frontiers in Psychology 9, 1-12. https://doi. org/10.3389/fpsyg.2018.01124

FIGURE 1: Zosh et al.'s (2018) model of play as a spectrum.

The interpretation of new ideas related to play informs how educators mediate their understanding and knowledge of play. Ryan and Northey-Berg (2014) also emphasise, however, that the settings within which educators are located, and their situated social, economic, political and cultural contexts, also inform their perceptions and understanding of play. Clarity on how educators perceive play provided the basis for the responsive design of the training curriculum.

In South Africa, a few studies have addressed educator perceptions of play. Aronstam and Braund (2016) explored the perceptions of play of 104 Grade R educators in 41 schools and ECD centres in the Western Cape. They found that educators had limited knowledge of the pedagogy of play and that their views, perceptions and knowledge of play should inform capacity-building programmes for ECD educators and practitioners. Ogunyemi and Ragpot (2015) reviewed educator and parent perceptions of play in South Africa and Nigeria and found that educators and parents with narrow views considered play to involve walking, clapping and singing outside classwork, whereas educators with a broader constructivist outlook considered play to be integral to the development of children. They make the case for a more supportive policy and procedural environment and for higher education institutions to provide programmes on play pedagogies. In South Africa, much of the literature on these higher education-based programmes focuses on the relationship between theory, practice and service learning (Gravett, Petersen \& Petker 2014; Petker \& Petersen 2014) and the need to understand child development (Henning 2014).

Ryan and Northey-Berg (2014) found, however, that while play as pedagogy is becoming more prominent in scholarly literature, few studies are based on what and how educators learn about play.

\section{Context and background}

The Eastern Cape, with $21.6 \%$ of all South Africa's schools, ranks among the largest, poorest and lowest-performing provinces in South Africa (Department of Basic Education 2018). During 2018, the Eastern Cape Department of Education reported that 20\% of children in Grade 1 in 2016 (36 000 children) had failed the grade. This represented the highest Grade 1 failure rate in South Africa (Linden 2018). Importantly, too, the poor performance of children in the Foundation Phase ${ }^{5}$ has also drawn attention to challenges with supply, skills and knowledge levels of Foundation Phase teachers. Green, Adendorff and Mathebula (2012) provide a succinct analysis of the growth in the supply of Foundation Phase educators in South Africa, particularly since 2008, and show that this growth is insufficient to meet the demand. They also found that there were still large numbers of unqualified and underqualified Foundation Phase educators in the system. These educators, including those who may be qualified, generally lack adequate knowledge and skills to make optimal use of resources in their classrooms to support active learning through play. In the Eastern Cape, this challenge is particularly acute, with 5389 public schools and approximately 132785 children enrolled in public Grade R classrooms in the Eastern Cape in 2017 (Department of Basic Education 2018).

Play Well \& Be Happy thus responded to the need for a systemic intervention to grow a teaching practice based on learning and teaching through play among Grade $\mathrm{R}$ practitioners $^{6}$ of 5-6-year-old children in primary schools and ECD centres in the Eastern Cape. In doing so, the programme situated the lack of play-based competencies among Grade $\mathrm{R}$ practitioners within their broader systemic challenges related to the low status of Grade $R$ within the Foundation Phase: poor working conditions and job insecurity of Grade $\mathrm{R}$ practitioners; the lack of formal qualifications among the majority of Grade $R$ practitioners; the continuing prevalence of corporal punishment in primary schools (reported by practitioners); overcrowded classrooms; and school management's lack of awareness and acknowledgement of the importance of Grade R practitioners (Isaacs, Spencer-Smith \& Roberts 2018).

Play Well \& Be Happy trained 966 Grade R and pre-primary practitioners and principals, which included 81 lead practitioners and facilitators, in 23 training sessions between 28 February and 30 November 2017. Across three districts in the Eastern Cape, it reached approximately 25000 children aged 5-7 years and delivered Play Well \& Be Happy kits to 966 classrooms.

5.The Foundation Phase includes Grade R to Grade 3.

6.'Practitioners' refer to those who are not yet qualified as Grade R or ECD educators. 


\section{The Play Well \& Be Happy approach to play}

This article does not elaborate on the design and rationale for the Play Well \& Be Happy programme and its related theory of change. Rather, it focuses explicitly on its approach to play.

The spectrum model as presented by Zosh et al. (2018) was adapted and adopted by the Play Well \& Be Happy programme to inform the design of the capacity-building programme for the Grade $\mathrm{R}$ practitioners. The following conceptual and operational definitions were applied by the programme (Takalani Sesame 2017):

- Free play. This means that the children choose how they are going to play and what to play with. Here the educator does not provide help and encourages the children to play, finding their own challenges and solutions on their own while the teacher observes.

- Guided play. This means that the teacher offers a challenge to the children, who structure their own play to solve the problem posed. The teacher observes, supports and guides the children as needed.

- Instructional play. This means that the teacher structures the play environment with specific activities and instructions, based on specific learning goals, so that the children can learn something specific that the teacher has decided upon. (p. 5)

By applying this model, the programme designed the curriculum and capacity-building methodology that would be relevant for the immediate contexts of the Eastern Cape Grade $\mathrm{R}$ practitioners. The capacity-building model draws to some extent on the available literature, albeit limited and contested, on teaching through play. In reviewing the literature to date, Ryan and Northey-Berg (2014) found that there were two kinds: those that highlighted the perceptions and understanding of play and those that focused on ECD educator education and professional development.

For Play Well \& Be Happy, play was conceptualised as a 'major method of active learning and creative problemsolving' for children (Takalani Sesame et al. 2017), which informed their quest to grow the repertoire of teaching through play skills, tools and strategies among an estimated 1000 Grade R practitioners. For Play Well \& Be Happy, through play, young children would be given the opportunity of overcoming emotional and social limitations that could potentially impede their executive functioning, drawing on Blanco and Ray (2011). Play was conceptualised to help children make a connection between their concrete understandings, their experiences and abstract events such as thoughts and feelings, as reflected by Landreth, Ray and Bratton (2009). By growing their understanding of learning through play, practitioners and educators would learn how to teach using play-based pedagogies. Evidence of playbased pedagogy was considered in relation to the use of the Play Well \& Be Happy resources in their classrooms and dividing children into play groups to allow the opportunity for play. In addition, four priority behaviours of practitioners were emphasised: (1) speak to children in calm tones, (2) bend down to their level during communications with children, (3) ask more open questions and (4) do not use aggressive language or tools to shame or punish children. In this way, it was hoped that practitioners would be encouraged to promote active learning through play that would enable the development of problem-solving skills, flexibility and the ability of the children to make connections to real-life situations (Partin et al. 2009).

The Play Well \& Be Happy programme was delivered over four implementation phases by a core team of facilitators, supported by the lead practitioners in the Eastern Cape. Each phase was delivered in a different region in the Eastern Cape: Phases 1 and 2 in the urban areas of East London and Port Elizabeth, respectively; then Phase 3 in rural Lusikisiki; and Phase 4 in the BCMM. The selection of the four geographic areas was made by the provincial Department of Education, in consultation with the programme implementers and funders. While Phases 1 through 3 targeted Grade R practitioners in public schools, Phase 4 targeted practitioners in ECD centres.

\section{Research methods and design}

This article draws on the components of the data collected for a broader evaluation research study, which aimed to provide an independent yet engaged perspective on the design, implementation and outcomes of Play Well \& Be Happy over the four successive implementation phases. The evaluation adopted design-based methods, and as such the programme design, as well as the instrumentation and ways of evaluating it, evolved with each successive implementation phase.

\section{Research questions}

The nature of the research questions of a study determines the research approach, which in turn determines the strategies used to collect and analyse data (Cresswell 2014). This article focuses on one aspect of the evaluation research data to answer the following questions:

- whether practitioners shifted their level of confidence in their self-reflections

- whether there was evidence of practitioner shifts in knowledge about learning through play

- if so, how this accorded with analysis of their observed practice of learning through play.

\section{Data collection methods}

Both quantitative and qualitative data were collected. The use of multiple data sources, which enabled insights from a number of vantage points (Henning, Van Rensburg \& Smit 2004), enhanced the validity of the study as proposed by Bryman (2006).

Data collection involved the methods shown in Figure 2. 


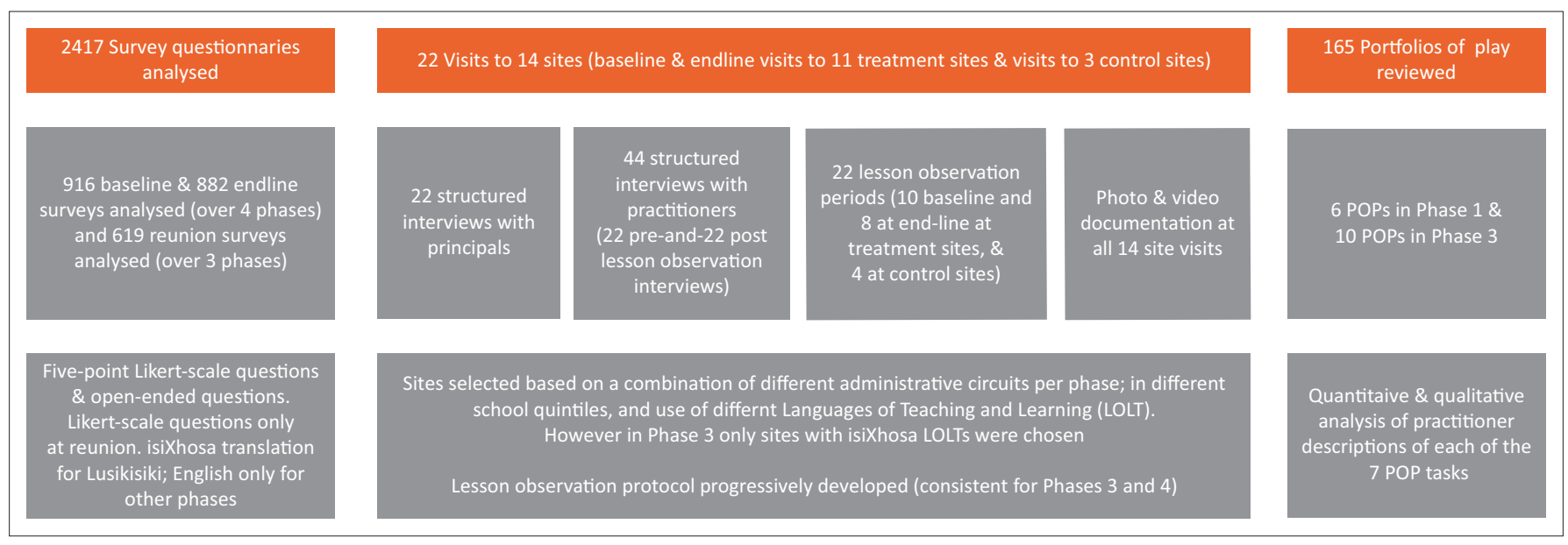

LOLT, Language of Learning and Teaching; POP, Portfolios of Play.

FIGURE 2: Data collection.

Changes in confidence, knowledge and practice of play were determined based on three data sources:

- Self-reported shifts in practitioners' confidence and knowledge practice ( $n=882$ matched questionnaires), solicited through a structured questionnaire at baseline and endline

- An analysis of practitioners' responses to open-ended questions designed to reflect their understanding of learning through play

- In-school lesson observations $(n=18)$ of case study Grade $\mathrm{R}$ practitioners in practice (in 14 'treatment' schools), where five case studies included lessons observed by the same practitioner $(n=10)$ at baseline and endline. ${ }^{7}$ These were compared to in-school lesson observations of Grade $\mathrm{R}$ practitioners in two 'control' schools.

\section{Survey questionnaires}

The survey questions at baseline and end line were largely matched in order to ascertain changes in practitioner opinions over time. Survey questions at baseline $(n=916)$ and end line $(n=882)$ included a combination of five-point Likert-scale questions that asked for opinions on various aspects of learning through play.

They also included three questions testing a practitioner's knowledge and understanding of aspects of play that required written responses:

- What do you understand by learning through play?

- What do children learn from learning through play?

- How do you organise your classroom for learning through play?

When analysing the practitioners' responses to the knowledge-based questions, a simple framework for judging changes in the practitioner's knowledge was used. An individual's baseline response was compared to their end line response on the same question, as follows:

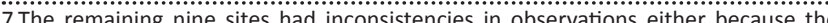
children were sent home at the last minute by the principal (Phase 1), because only baseline visits were conducted (Phase 2), because the class was taught by the baseline visits were conducted (Phase 2), because the class was taught by the
principal at end line and practitioner at baseline (Phase 4 ) or because the evaluators principal at end line and practitioner at baseline (Phase 4) or because the evalua
discovered that the practitioner did not attend the training at all (Phase 4).
- a positive shift (improved understanding from baseline to end line)

- a negative shift (regression in understanding from baseline to end line)

- no shift (no change in understanding from baseline to end line).

For Phases 3 and $4,{ }^{8}$ a more detailed coding rubric was developed to analyse the matched open-ended questions, and the responses were blind-coded by two researchers. This included attention to three levels of possible shifts:

- Level 1: attitudes and perceptions of play

- Level 2: knowledge of play

- Level 3: practice of play.

Moreover, the quality of responses were coded as 0 (incoherent or off-topic), 1 (basic understanding), 2 (intermediate understanding) and 3 (advanced understanding).

Table 1 shows the data analysis frameworks as applied to the survey questionnaire responses.

During Phase 3, evaluators coded a random sample of $20 \%$ of responses to the matched open-ended questions pertaining to knowledge of learning through play. In Phase 4, all responses to the open-ended questions were coded. The difference in total score from baseline to end line was a rough quantitative measure of change in understanding. This was useful to measure overall trends, in the absence of an assessment rubric.

\section{Lesson observations at treatment and control schools}

In applying a qualitative methodology, the case study method was selected because it provides an opportunity to highlight specific experiences (such as, in this case, the integration of play in classroom practice), bounded and informed by specific contexts (Merriam 1998). A purposive sampling strategy was employed. Treatment schools were selected in 8.In Phase 2 there was a lighter touch evaluation, to stay within the budget parameters, and as the urban context of Port Elizabeth was considered sufficiently similar to that of East London. 
TABLE 1: The survey analysis rubric for open questions.

\begin{tabular}{|c|c|c|c|}
\hline Elementary rubric & Practitioner outcomes & Change framework & Coding rubric \\
\hline $\begin{array}{l}\text { Level 1: Attitudes } \\
\text { and perceptions } \\
\text { of play }\end{array}$ & $\begin{array}{l}\text { Are more confident in providing play exercises } \\
\text { as a vehicle for learning }\end{array}$ & \multirow{2}{*}{$\begin{array}{l}\text { A simple framework for judging changes } \\
\text { in practitioner knowledge, by comparing } \\
\text { an individual's baseline response to their } \\
\text { end line response on the same question, } \\
\text { as follows: } \\
\text { - a positive shift (improved understanding } \\
\text { from baseline to end line) } \\
\text { - a negative shift (regression in } \\
\text { understanding from baseline to end line) } \\
\text { - no shift (no change in understanding from } \\
\text { baseline to end line). }\end{array}$} & \multirow{2}{*}{$\begin{array}{l}\text { What do you understand by learning through play? } \\
\text { Incoherent or off-topic: scored } 0 \\
\text { Basic understanding: scored } 1 \\
\text { Intermediate understanding: scored } 2 \\
\text { Advanced understanding: scored } 3 \\
\text { What do children learn from learning through play? } \\
\text { Incoherent or off-topic: scored } 0 \\
\text { Basic understanding: scored } 1 \\
\text { Intermediate understanding: scored } 2 \\
\text { Advanced understanding: scored } 3\end{array}$} \\
\hline $\begin{array}{l}\text { Level 2: Knowledge } \\
\text { of play }\end{array}$ & $\begin{array}{l}\text { Know how to provide play exercises as a vehicle } \\
\text { for learning }\end{array}$ & & \\
\hline \multirow[t]{3}{*}{$\begin{array}{l}\text { Level 3: Practice } \\
\text { of play }\end{array}$} & $\begin{array}{l}\text { Uses LEGO Duplo bricks and Takalani Sesame materials } \\
\text { to support active learning through play and reflects on } \\
\text { children's responses to materials }\end{array}$ & & \multirow{3}{*}{$\begin{array}{l}\text { How do you organise your classroom for learning } \\
\text { through play? } \\
\text { Incoherent or off-topic: scored } 0 \\
\text { Basic understanding: scored } 1 \\
\text { Intermediate understanding: scored } 2 \\
\text { Advanced understanding: scored } 3\end{array}$} \\
\hline & $\begin{array}{l}\text { Sets up and manages the use of play stations in their } \\
\text { classrooms and helps children manage materials }\end{array}$ & & \\
\hline & $\begin{array}{l}\text { Evidence of four behaviours: (1) asks more open questions, } \\
\text { (2) gets down to children's level, (3) does not use aggressive } \\
\text { gestures or tools and (4) speaks more gently }\end{array}$ & & \\
\hline
\end{tabular}

TABLE 2: Lesson observation protocol.

\begin{tabular}{|c|c|c|c|c|c|}
\hline Theory of change outcomes for practitioners and children & Never & $\begin{array}{c}\text { To a limited } \\
\text { extent }\end{array}$ & Somewhat & $\begin{array}{l}\text { Most of } \\
\text { the time }\end{array}$ & Extensively \\
\hline \multicolumn{6}{|l|}{ In this guided lesson the practitioner ... } \\
\hline Used available equipment (LEGO ${ }^{\circledR}$ Duplo bricks, play mat or other resources) effectively & 0 & 1 & 2 & 3 & 4 \\
\hline Set up and managed play stations in their classroom & 0 & 1 & 2 & 3 & 4 \\
\hline Made learning fun and engaging through guided play & 0 & 1 & 2 & 3 & 4 \\
\hline Made learning fun and engaging through free play & 0 & 1 & 2 & 3 & 4 \\
\hline Made learning fun and engaging through instructional play & 0 & 1 & 2 & 3 & 4 \\
\hline Included children of all abilities, including children with special needs & 0 & 1 & 2 & 3 & 4 \\
\hline Was confident in integrating play as part of their teaching & 0 & 1 & 2 & 3 & 4 \\
\hline Asked open questions & 0 & 1 & 2 & 3 & 4 \\
\hline Got down to the children's level & 0 & 1 & 2 & 3 & 4 \\
\hline Used a calm tone of voice when speaking to the children & 0 & 1 & 2 & 3 & 4 \\
\hline Used an aggressive tone of voice or actions when speaking to the children, so as to break down the children & 4 & 3 & 2 & 1 & 0 \\
\hline Used positive words or actions so as to affirm the children & 0 & 1 & 2 & 3 & 4 \\
\hline Total & - & - & - & - & 48 \\
\hline Spent most of the available time in enjoyable 'learning through play' activity & 0 & 1 & 2 & 3 & 4 \\
\hline $\begin{array}{l}\text { Communicated with the teacher frequently (chorus responses are excluded from this definition of } \\
\text { communication with the teacher) }\end{array}$ & 0 & 1 & 2 & 3 & 4 \\
\hline Communicated with each other frequently & 0 & 1 & 2 & 3 & 4 \\
\hline Worked together and cooperated with other children & 0 & 1 & 2 & 3 & 4 \\
\hline Respected other children & 0 & 1 & 2 & 3 & 4 \\
\hline Managed their own play (by choosing and/or initiating the play activities) & 0 & 1 & 2 & 3 & 4 \\
\hline Total & - & - & - & - & 24 \\
\hline
\end{tabular}

$\dagger$, In addition, the researcher reflected on how the children responded to the ECD practitioner, using statements.

each district, such that the two schools came from separate administrative circuits; ${ }^{9}$ were different school quintiles; ${ }^{10}$ and used different languages of teaching and learning. Where possible, case study schools were visited at baseline and again at end line. The control schools were identified by the Eastern Cape Department of Education as being in the same district as the treatment schools (but not engaged in the Play Well \& Be Happy programme).

The qualitative data collected through the school visits is not the focus of this article. Instead, we have presented the coding rubrics and ways in which the data was collated among the case study practitioners to offer a broad-brush measure of changes in practice. Classroom observations 9.Each school district in the Eastern Cape contains two administrative circuits.

10.Schools in South Africa are categorised into quintiles according to the level of affluence of the community surrounding the schools. Quintile 1 schools are situated in the poorest communities, and Quintile 5 communities in the wealthiest. Quintiles 1 to 3 receive a higher government subsidy and do not usually charge school fees. focused on how the Grade $\mathrm{R}$ practitioner facilitated active learning through play in general, and how they used the Play Well \& Be Happy materials in particular. A lesson observation protocol, as shown in Table 2, was developed to aid the interpretation of our observations.

A total score out of 72 was awarded for the baseline and end line guided play lesson observation, which included a total of 48 for practitioner outcomes and 24 for outcomes displayed by children. These were converted to percentages and compared. Positive shifts, negative shifts or no change from baseline to end line were noted for each case study observation.

\section{Ethical considerations}

This research followed the United Nations International Children and Education Fund (UNICEF) ethical guidelines for conducting research involving children (UNICEF 2015). 
In so doing, several ethical approval processes have been obtained, namely ethical approval from the Ethics Committee of the University of Johannesburg's Faculty of Education (ethical clearance number 2017-015); research permission from the provincial Department of Basic Education (Eastern Cape); and voluntary informed consent to participate in the research from the teacher trainers and Grade $\mathrm{R}$ practitioners (in their surveys). Furthermore, all data collected were anonymised, and all participants had the right to withdraw from the research at any point in time. There was no harm foreseen as a result of being part of the research.

\section{Results}

In this section we explain how practitioners self-reported on their confidence and knowledge. This is the augmented with how we analysed responses to survey questions, which were designed to solicit their understanding of learning through play. This is contrasted with the practice of play observed for the case study practitioners.

\section{Practitioner reflections on changes in confidence $(n=882)$}

In all four phases there was a significant positive shift in the reported level of confidence with providing play experiences (moderate to large effect sizes), as shown in Table 3.

\section{Practitioner reflections on changes in knowledge and practice $(n=882)$}

The practitioners also reported very positively on the materials, on their learning about planning and their promotion of active learning through play, as well as their children's ability to be organised into groups and the possibility of using guided play techniques.

As shown in Table 4, in all three phases, there was close to unanimous agreement that the LEGO $^{\circledR}$ Duplo Bricks and Takalani materials had supported learning through play in the classroom. There was a bigger variation between phases on whether children knew how to be organised into play stations. The highest agreement levels were in the BCMM $(91.7 \%)$ and the lowest in PE (78.3\%).

In terms of the priority behaviours of the practitioners in their interaction with the children, the practitioners first selfreported on these. The practitioners in all phases but the first were asked to respond to four statements using a five-point Likert-scale. The results shown in Table 5 indicate that there was extensive agreement with all four statements. Thus, the practitioners felt that they asked more open-ended questions;

TABLE 3: Change in reported levels of confidence with providing play experiences.

\begin{tabular}{llll}
\hline Variable & Significance & Effect size & Direction of change \\
\hline East London & Yes & 0.069 (moderate) & Positive \\
Port Elizabeth & Yes & 0.082 (moderate) & Positive \\
Lusikisiki & Yes & 0.151 (large) & Positive \\
Buffalo City & Yes & 0.170 (large) & Positive \\
\hline
\end{tabular}

Note: Statement (asked at both baseline and end line): I am confident in providing play experiences that will help the children to learn. spoke more calmly to the children; listened more to the children; bent down more to the children's level; and punished or shamed the children in front of the class less (compared with all cases before the training programme).

The results in Table 5 provide a glowing response to the extent to which the expectations of the programme were met: the practitioners were overwhelmingly positive. This at least demonstrates that they were aware of the behaviours expected of them after the short 5-week course.

A slightly more nuanced view on the actual implementation of the hoped-for expectations was evident in their descriptions of the challenges that they faced when trying to enact the programme expectations. Table 6 highlights the main challenges that practitioners experienced during their attempts at teaching through play.

TABLE 4: Levels of agreement with various Likert-scale questions, by location at end line.

\begin{tabular}{|c|c|c|c|c|}
\hline \multirow[t]{2}{*}{ Statement } & \multicolumn{4}{|c|}{$\%$ agreeing or strongly agreeing } \\
\hline & EL & PE & Lusikisiki & BCMM \\
\hline $\begin{array}{l}\text { The LEGO }{ }^{\circledR} \text { Duplo bricks and Takalani materials } \\
\text { make it easier to support 'learning through } \\
\text { play' in class. }\end{array}$ & - & 98.7 & 99.6 & 100.0 \\
\hline $\begin{array}{l}\text { Compared with my original ECD practitioner } \\
\text { training, I learned more about how to plan } \\
\text { and promote active learning though play in } \\
\text { this Play Well \& Be Happy training. }\end{array}$ & 90.4 & 91.9 & 98.9 & 90.4 \\
\hline $\begin{array}{l}\text { The children in my class now know how to } \\
\text { be organised into groups of five to six so } \\
\text { they can all be playing. }\end{array}$ & 87.7 & 78.3 & 81.9 & 91.7 \\
\hline $\begin{array}{l}\text { Guided play is possible with all children, } \\
\text { including those with special needs. }\end{array}$ & - & 85.2 & 87.9 & 85.2 \\
\hline
\end{tabular}

EL, East London; PE, Port Elizabeth; BCMM, Buffalo City Metropolitan Municipality; ECD Early Childhood Development.

TABLE 5: Levels of agreement with Likert-scale questions related to practitioner behaviour, by location at end line.

\begin{tabular}{|c|c|c|c|c|}
\hline \multirow[t]{2}{*}{ Statement } & \multicolumn{4}{|c|}{$\%$ agreeing or strongly agreeing } \\
\hline & EL & $\mathrm{PE}$ & Lusikisiki & BCMM \\
\hline I ask the children more open-ended questions. & - & 91.2 & 98.5 & 93.8 \\
\hline I speak more calmly to the children. & - & 86.4 & 90.8 & 91.5 \\
\hline $\begin{array}{l}\text { I bend down more so as to speak at the } \\
\text { children's level. }\end{array}$ & - & 84.2 & 95.7 & 96.3 \\
\hline $\begin{array}{l}\text { I punish/shame the children more in front of } \\
\text { the class. }{ }^{11}\end{array}$ & - & 85.2 & 96.9 & 98.8 \\
\hline
\end{tabular}

EL, East London; PE, Port Elizabeth; BCMM, Buffalo City Metropolitan Municipality.

TABLE 6: Top challenges in implementing Play Well \& Be Happy, by location.

\begin{tabular}{llll}
\hline East London & Port Elizabeth & Lusikisiki & Buffalo City \\
\hline $\begin{array}{l}\text { Poor learner } \\
\text { behaviour or lack of } \\
\text { cooperation (50.6\%) }\end{array}$ & $\begin{array}{l}\text { Lack of space } \\
(58.1 \%)\end{array}$ & $\begin{array}{l}\text { Lack of space } \\
(44.1 \%)\end{array}$ & $\begin{array}{l}\text { Lack of space } \\
(36.9 \%)\end{array}$ \\
$\begin{array}{l}\text { Lack of space } \\
(42.0 \%)\end{array}$ & $\begin{array}{l}\text { Not wanting to } \\
\text { share or take turns } \\
\text { or rotate play } \\
\text { stations (34.9\%) }\end{array}$ & $\begin{array}{l}\text { Not wanting to } \\
\text { share or take turns } \\
\text { or rotate play } \\
\text { stations (41.3\%) }\end{array}$ & $\begin{array}{l}\text { Not wanting to } \\
\text { share or take turns } \\
\text { or rotate play } \\
\text { stations (35.7\%) }\end{array}$ \\
$\begin{array}{l}\text { Too many children } \\
(7.4 \%)\end{array}$ & $\begin{array}{l}\text { Too many children } \\
(17.8 \%)\end{array}$ & $\begin{array}{l}\text { Poor learner } \\
\text { behaviour or lack of } \\
\text { cooperation (24.2\%) }\end{array}$ & $\begin{array}{l}\text { Insufficient } \\
\text { resources }(14.3 \%)\end{array}$ \\
$\begin{array}{l}\text { Insufficient } \\
\text { resources (7.0\%) }\end{array}$ & $\begin{array}{l}\text { Insufficient } \\
\text { resources (17.0\%) }\end{array}$ & $\begin{array}{l}\text { Insufficient } \\
\text { resources (21.7\%) }\end{array}$ & $\begin{array}{l}\text { Poor learner } \\
\text { behaviour or lack of } \\
\text { cooperation (4.8\%) }\end{array}$ \\
$\begin{array}{l}\text { Children wanting to } \\
\text { play all the time } \\
(6.6 \%)\end{array}$ & $\begin{array}{l}\text { Poor learner } \\
\text { behaviour or lack } \\
\text { of cooperation }\end{array}$ & $\begin{array}{l}\text { Too many children } \\
(14.2 \%)\end{array}$ & $\begin{array}{l}\text { Some children } \\
\text { not wanting to } \\
\text { participate or } \\
\text { wanting to play } \\
\text { alone (3.6\%) }\end{array}$ \\
\hline
\end{tabular}

11.In this case, the percentages shown are for disagree/strongly disagree, as this is a negatively-phrased statement. 
TABLE 7: Analysis of practitioner understanding of learning through play, Phases 3 and 4.

\begin{tabular}{|c|c|c|c|c|c|c|c|c|}
\hline \multirow[t]{3}{*}{ Variable } & \multicolumn{4}{|c|}{ Lusikisiki (Phase3)† } & \multicolumn{4}{|c|}{ Buffalo City (Phase 4) $\$$} \\
\hline & \multicolumn{2}{|r|}{ Baseline } & \multicolumn{2}{|r|}{ End line } & \multicolumn{2}{|r|}{ Baseline } & \multicolumn{2}{|r|}{ End line } \\
\hline & $\%$ & $n$ & $\%$ & $n$ & $\%$ & $n$ & $\%$ & $n$ \\
\hline Mean character count & - & 153 & 145 & - & - & 163 & - & 117 \\
\hline Median code & - & $\begin{array}{c}1 \\
\text { (basic } \\
\text { understanding) }\end{array}$ & - & $\begin{array}{c}2 \\
\text { (intermediate } \\
\text { understanding) }\end{array}$ & - & $\begin{array}{c}2 \\
\text { (intermediate } \\
\text { understanding) }\end{array}$ & - & $\begin{array}{c}1 \\
\text { (basic } \\
\text { understanding) }\end{array}$ \\
\hline Number of responses coded 0 (incoherent or off-topic) & - & 1 & - & 1 & & 4 & - & 10 \\
\hline Number of responses coded 2 (intermediate understanding) & 28 & 15 & 47 & 25 & 53 & 42 & 32 & 23 \\
\hline Number of responses coded 3 (advanced understanding) & 4 & 2 & 3 & 2 & 5 & 4 & 7 & 5 \\
\hline
\end{tabular}

$\dagger$, Lusikisiki (Phase3): Statistically significant change? Yes (increased understanding); effect size -0.062 (moderate).

$\$$, Buffalo City (Phase 4): Statistically significant change? Yes (decreased understanding); effect size -0.083 (moderate).

This provides a contrast to the overwhelmingly positive self-reporting on uptake of the programme expectations. It suggests that, while the practitioners were aware of what was expected, they nevertheless faced numerous challenges in enacting these expectations in their classrooms.

\section{Practitioner knowledge of learning through play}

In all phases, practitioners were asked, 'What is your understanding of learning through play?' and 'What do you think the children learn when you use "playful learning" in your classroom?'

Across all phases, participants reflected a basic understanding of learning through play, but there were modest and uneven shifts in understanding play from baseline to end line.

In Phase 1 (East London), 45.8\% of practitioners showed an improvement in understanding from baseline to end line. In Phase 2 (Port Elizabeth), because they showed a good understanding of play at baseline, $28 \%$ of practitioners showed an improvement in understanding. In Phase 3 (Lusikisiki) and Phase 4 (Buffalo City), a more detailed coding protocol was applied, as shown in Table 7, which revealed that Lusikisiki practitioners showed a significant improvement in understanding from baseline to end line with moderate effect size, while Buffalo City practitioners showed a significant decrease in understanding with a moderate effect size.

In general, $\mathrm{BCMM}$ practitioners scored higher at baseline than at end line, thus showing a negative change with a moderate effect size. The reason for this may be attributable to less time being given to practitioners to answer the survey at end line compared to more time given when answering the baseline questionnaire. This is evident in the lower mean for the character counts at end line.

\section{Observations of practitioners' practice of play}

The following indicators of a practice of play were considered through the lesson observations: the use of play equipment, the running of play stations and the four explicit behaviours expected from the teachers (asking open questions, getting down to the children's level, not using aggressive gestures or tools and speaking with calm and gentle tones to the children).
Scores were allocated as per the lesson observation protocol for 'used available [play] equipment effectively' and 'set up and managed play stations in the classroom' and were then tallied. These scores are shown in Table 8.

Overall, the average total score increased from 10 points at baseline to 18 points at end line (which was a statistically significant difference). ${ }^{12}$

The average end line score is $56.3 \%$ of the total possible score for these two indicators. As a point of comparison, at seven control lesson observations, the average score obtained was $51.8 \%$. Thus, the trained practitioners of Play Well \& Be Happy obtained a slightly better score than those who were untrained (but this difference was not statistically significant). ${ }^{13}$

In the case of the observed lessons, scores for the practitioners' interactions with the children were allocated as per the lesson observation protocol for the five aspects indicated, which were then tallied (see Table 9).

Overall, the total score decreased from 48 points at baseline to 47 points at end line (but this difference was not significant). ${ }^{14}$

The average end line score is $58.8 \%$ of the total possible score for these five indicators. As a point of comparison, in the seven control lessons observed, the average score obtained was very similar, at $56.4 \%$ (and the difference between control and treatment schools was not significant). ${ }^{15}$

12.A two-tailed Wilcoxon signed-rank test was conducted on the pre- and posttraining "play' scores of the treatment school practitioners. The post-training scores (median $=2.5$ ) were higher than the pre-training scores (median $=1)$, and the differences were significant (the test statistic $=3$, which is less than the critical value of 4 at a $5 \%$ level).

13.A two-tailed Mann-Whitney $U$ test was conducted on the 'play' scores of the control school practitioners (Group A) and on those of the treatment schoo practitioners (Group B) at endline. The scores for treatment school practitioners ( median $=2.5$ ) were higher than for the control practitioners (median $=2, U=48$, $p=0.611$ ); however, the difference is not significant at the $5 \%$ level.

14.A two-tailed Wilcoxon signed-rank test was conducted on the pre- and posttraining 'interaction with children' scores of the treatment school practitioners. The post-training scores (median $=2.5$ ) were lower than the pre-training scores (median $=3$ ), but the differences were not significant (the test statistic $=9$, which is more than the critical value of 4 at a $5 \%$ level).

15.A two-tailed Mann-Whitney $U$ test was conducted on the 'interaction with children' scores of the control school practitioners (Group A) and on those of the tre scores of the control school practitioners (Group A) and on those the treatment school practitioners (Group 1 ) at end (reatment school practitioners (median $=2.5$ ) were higher than for the control practitioners (median $=2, \mathrm{U}=337.5, p=0.834$ ), but the difference is not significant at the $5 \%$ level. 
TABLE 8: Practitioners' baseline and end line scores on the use of play materials and setting up play stations.

\begin{tabular}{lccc}
\hline Variable & Baseline score & End line score & Change \\
\hline Lusikisiki P1 & 1 & 6 & +5 points \\
Lusikisiki P2 & 2 & 1 & -1 point \\
Lusikisiki P3 & 4 & 5 & +1 point \\
Buffalo City P1 & 3 & 6 & +3 points \\
\hline Total points & $\mathbf{1 0}$ & $\mathbf{1 8}$ & $+\mathbf{8}$ points \\
\hline Median & $\mathbf{2 . 5}$ & $\mathbf{4 . 5}$ & - \\
\hline
\end{tabular}

P, practitioner.

TABLE 9: Practitioners' baseline and end line scores on their manner of interaction with the children.

\begin{tabular}{lccc}
\hline Variable & Baseline score & End line score & Change \\
\hline Lusikiski P1 & 9 & 15 & +6 points \\
Lusikiski P2 & 11 & 6 & -5 points \\
Lusikiski P3 & 16 & 13 & -3 points \\
Buffalo City P1 & 12 & 13 & +1 point \\
\hline Total & $\mathbf{4 8}$ & $\mathbf{4 7}$ & $\mathbf{- 1}$ point \\
\hline Averages & $\mathbf{1 2 . 0}$ & $\mathbf{1 1 . 8}$ & $\mathbf{- 0 . 2}$ \\
\hline
\end{tabular}

P, practitioner.

If one breaks down the overall score into individual aspects, it is clear that asking open-ended questions is a major omission across the board. Out of all seven lessons given by trained teachers of Play Well \& Be Happy observed at end line ${ }^{16}$ in only two did the practitioner receive a score of better than 0 ('never'): one received a 1 ('to a limited extent') and one a 2 ('somewhat'). On the other end of the spectrum, avoiding aggressive words and actions was positive throughout: out of the same seven lessons mentioned, in only two did the practitioner receive a score of less than 4 ('extensively'): two received a score of 3 ('most of the time').

\section{Discussion}

We return now to reflect on our research questions before and after the Play Well \& Be Happy intervention:

- whether practitioners shifted their level of confidence in their self-reflections

- whether there was evidence of practitioner shifts in knowledge about learning through play

- if so, how this accorded with analysis of their observed practice of learning through play.

In all four phases there was a significant positive shift in the reported level of confidence with providing play experiences (moderate to large effect sizes). Similarly, there was enthusiastic positive self-reporting on their improved knowledge, utility and implementation of the changes in behaviour expected from the practitioners.

It is clear from the data that self-reported evidence (collected through the survey) is exceptionally positive, with practitioners reporting positively on desired attributes both before and after the intervention. While positive shifts were evident, this was from very high baseline levels. This was made worse in some cases by the skewed phrasing

16.This includes the four practitioners observed at both baseline and end line and a further three observed only at end line. of questions included in the instrumentation, such as 'Do you agree or disagree that you now do X more than before?' As such, while the self-reporting may be interpreted to show practitioner enthusiasm and confidence in their approach to teaching through play, this seems to be of little substantive value.

There was more nuance and useful qualitative data obtained from the analysis of the open-ended questions included in the survey. Open questions like 'What do you understand by learning through play?' were posed, and the responses to these were coded in more detailed ways with each design cycle. This provided some written evidence of the practitioners' developing understanding of the main ideas.

Across all phases, participants reflected a basic understanding of learning through play but uneven shifts in understanding of play from baseline to end line. Initially a simple code of positive, negative or no shift in understanding was applied. By Phase 4, the responses were blind-coded using an agreed coding rubric. The type of activity undertaken as part of the evaluation research ought to be included in the assessment and feedback practices of the Play Well \& Be Happy course in future.

The real test of changes in practice was only evident at the coalface, when practitioners were observed teaching in their classrooms. It is seldom that such site visits and lesson observations can be included within the available resources for a training intervention. In this case, careful selection of case studies allowed for 22 site visits to be included. However - as the data revealed - within the complexity of a challenging schooling system, only five cases included both pre- and post-intervention observations of the same practitioner in the same classroom. Table 10 offers a summary of this in relation to shifts from baseline to end line observations and then in comparison to the control schools.

This quantification of lesson observation data is crude, but suggests that there was evidence (at least among the five case study practitioners) that there was significant improvement in relation to teaching through play with the use of play equipment and play stations. We would describe these behaviours as the 'form' of what was expected from the Play Well \& Be Happy programme: a shift from whole-class teaching without play equipment to managed play stations with play equipment.

This is perhaps not surprising in a South African policy context that places more emphasis on the availability of play resources and infrastructure, developing safe play spaces, and facilitating parent education and capacity-development programmes on the importance of play (A Chance to Play Southern Africa 2017). One has to be realistic about what is achievable in a short course. Achieving such a shifts towards better availability of play resources, great confidence and greater awareness of the importance of play, as well as the kinds of behaviours expected from practitioners in their 
TABLE 10: Summary of observation findings.

\begin{tabular}{llll}
\hline Focus area & $\begin{array}{l}\text { Description of findings } \\
\text { (pre to post) }\end{array}$ & $\begin{array}{l}\text { Stat analysis of findings } \\
\text { (pre to post) }\end{array}$ & Description of findings (treatment vs control) \\
\hline $\begin{array}{l}\text { Use of play equipment and } \\
\text { running of play stations }\end{array}$ & $\begin{array}{l}\text { Overall increase in total } \\
\text { score and in median }\end{array}$ & $\begin{array}{l}\text { Significant improvement } \\
\text { from pre to post }\end{array}$ & $\begin{array}{l}\text { Treatment practitioners obtained slightly higher } \\
\text { scores (and had higher median score) than control }\end{array}$ \\
$\begin{array}{l}\text { Interactions with children } \\
\text { (the five behaviours) }\end{array}$ & $\begin{array}{l}\text { Slight decrease in total } \\
\text { score and median, overall }\end{array}$ & No significant difference & $\begin{array}{l}\text { Treatment practitioners obtained very slightly higher } \\
\text { scores and median score than control }\end{array}$ \\
\hline
\end{tabular}

classroom, are important steps in the right direction. They are perhaps all that can be expected from a short 5-week training intervention.

The evidence of any shifts in practice with regard to the 'hoped-for' practitioner behaviours was more elusive, with no significant difference observed from baseline to end line among the five case study practitioners. The positive shifts in confidence and knowledge did not yet accord with the practitioners' observed practice of learning through play. Practitioners demonstrated the clearest difficulties with understanding the practice of applying different play strategies, asking open questions and enabling children to manage their own play. This points to the need for a longer professional development intervention, which would provide more examples and clarity on the meaning of different play strategies and the appropriate conditions in which to apply each of them. It should be borne in mind that the lessons were being observed, which may have changed the normal practice of the practitioner. However, the data reveals at the very least that practitioners were more aware of what was expected of them in relation to their interactions with the children and were able to model this behaviour to the observer (other than in the case of asking more openended questions).

The inclusion of 'control schools' in the research design was exploratory. Their selection was made by the provincial Department of Education based on being in the same district as the treatment school being observed. However, after collecting the data it was clear that the control schools had not been adequately matched with the treatment schools (in terms of a whole range of socio-economic, infrastructure and practitioner qualification and experience indicators). The absence of this detailed matching - and preferably including standardised measures of learner outcomes - meant that the treatment and control baselines were not sufficiently comparable.

\section{Conclusion}

The Play Well \& Be Happy research design made clear the complexity of designing, implementing and researching a large-scale intervention simultaneously. The four-phase design allowed for improvement in how the programme was conceptualised and reflected upon. However, by Phase 4 there still remained areas for improvement, with a particular need to include some formal assessment as part of the programme (via course materials or a written assignment), rather than being included as open questions in a research questionnaire. The coding and feedback of these responses needed to be integrated into the programme design.
Nevertheless, Play Well \& Be Happy represents an important exploratory and systematic province-wide intervention on building Grade R and ECD practitioner capacity in learning and teaching through play in the Eastern Cape. The programme had wide-ranging positive effects on initial practitioner awareness of play, their levels of confidence and their understanding and practice of play, and it provided important joyful learning opportunities for the estimated 25000 children who showed enthusiasm towards the LEGO ${ }^{\circledR}$ and Takalani materials that the programme provided.

The experience laid an important basis for a further improved systemic and sustainable intervention focused on growing the capabilities of practitioners and educators and deepening their practice of play. We believe that more formalised focus, funding and dedication to continuous professional development and training of practitioners in the Eastern Cape in terms of best practices in ECD in general, and specifically the role of play, will help strengthen the systemic capacity of the Eastern Cape Department of Education (DOE) for effective ECD delivery, thereby improving the lives of all the children in the province. This article contributes to ensuring that the Play Well \& Be Happy experience and lessons are widely shared with the public, government, ECD non-government organisations and the research community.

\section{Acknowledgements}

This article is a product of the collective effort of a number of individuals and stakeholders. The authors thank the approximately 1000 Grade R and pre-primary practitioners and principals for their participation in the evaluation of the Play Well \& Be Happy programme. The authors acknowledge the principals at five Early Childhood Development centres and nine primary schools who allowed them to conduct interviews and observe their practitioners and their practice of play.

The core implementation team, Ms Margaret Irvine, Dr Daisy Reddy, Ms Colleen Forsyth, Ms Cherrylyn MacMaster and the late Ms Busi Sokopo, supported the authors extensively with evaluation activities. Ms Koleka Lwana and Ms Glory Ndabeni played a central role in East London and Lusikisiki, respectively.

Meetings and conference calls with the Sesame Workshop team based in New York provided guidance on the design of the evaluation methodologies and ways in which the authors could improve the evaluation process. The authors thank Dr Jennifer Kotler (Head of Research and Evaluation), Ms Alyson Moskowitz (Project Manager) and Ms Nada Elattar (Director of Educational Programmes for the International Social Impact Department) for their warm support. 
The authors also give special thanks to Mr Michael Renvillard (Initiatives Lead for South Africa), Dr Jill Popp and Mr Vincent Doyle (all from the LEGO ${ }^{\circledR}$ Foundation, who funded the Play Well \& Be Happy programme). The authors acknowledge the Mai Family Foundation, who provided initial funding for the Takalani Sesame Eastern Cape outreach initiative, which served as an informative pilot for the PW\&BH expansion initiative.

Finally, the authors thank the Kelello-University of Johannesburg research team: Ms Rene Weston (Project Coordinator), Mr Andile Mbali (Field Worker and Case Study Writer), Ms Pam Maxakato (Field Worker), Ms Koleka Ntantiso (Field Worker and Case Study Writer), Ms Yolisa Madolo (Translator), Ms Zola Thompson (Translator), Dr Kaya Tshabalala (Field Worker), Ms Gail Van Heerden (Data Capturer) and Ms Zahraa Parker (Data Capturer).

\section{Competing interests}

The authors declare that they have no financial or personal relationships that may have inappropriately influenced them in writing this article.

\section{Authors' contributions}

S.I. coordinated the collaboration between the authors; conducted the literature review, which was integrated in the findings section; put the initial drafts together; and edited the final version. S.B. wrote the research methodology section. G.S.S. added the evaluation results in the findings section and provided edits to the article. N.R. wrote the abstract and discussion and edited the article.

\section{Funding information}

The PW\&BH programme and the programme evaluation was funded by the LEGO $^{\circledR}$ Foundation through their partnership with the Sesame Workshop, and their South African counterpart, Takalani Sesame which enjoys a partnership with the Eastern Cape Department of Education and the Buffalo City Metropolitan Municipality.

\section{References}

Aronstam, S. \& Braund, M., 2016, 'Play in Grade R classrooms: Diverse teacher perceptions and practices', South African Journal of Childhood Education 5, 1-10. https://doi.org/10.4102/sajce.v5i3.242

Atmore, E., 2013, 'Early childhood development in South Africa - Progress since the end of apartheid', International Journal of Early Years Education 21(2-3), 152-162. https://doi.org/10.1080/09669760.2013.832941

Atmore, E., Van Niekerk, L. \& Ashley-Cooper, M., 2012, 'Challenges facing the early childhood development sector in South Africa', viewed 20 August 2018, from http://www.nda.org.za/home/43/files/Research Reports/Challenges-facing-ECDSector-in-SA-Prof-Atmore.pdf

Blanco, P. \& Ray, D., 2011, 'Play therapy in elementary Schools: A best practice for improving academic achievement', Journal of Counseling and Development. 89(2) 235-243 https://doi.org/10.1002/j.1556-6678.2011.tb00083.x

Brooker, L., Blaise, M. \& Edwards, S., 2014, The SAGE handbook of play and learning in early childhood, SAGE Publications, London.

Bryman, A., 2006, 'Integrating quantitative and qualitative research. How is it done?' Qualitative Research 6(1), 97-113. SAGE Publications. https://doi.org/10.1177/ 1468794106058877
Cresswell, J.W., 2014, Research design. Qualitative, quantitative and mixed methods approaches, SAGE Publications, Thousand Oaks, CA.

Department of Basic Education, 2018, School realities 2017, Department of Basic Education, Pretoria, viewed 20 August 2018, from https://www.education gov.za/ Portals/0/Documents/Reports/2017\%20School\%20Realities.pdf?ver=2019-0326-095601-773

Department of Education, 2001, Education white paper 5 on early childhood education, Department of Education, Pretoria.

Edwards, L.M., 2017, 'Early childhood educators' perspectives of play in preschoo classrooms', A Dissertation presented to the Faculty of the Educational Leadership Doctoral Program, Western Kentucky University, Kentucky, viewed 20 February 2019, from https://digitalcommons.wku.edu/cgi/viewcontent.cgi?article=1122\& context=diss

Gravett, S., Petersen, N. \& Petker, G., 2014, 'Integrating foundation phase teacher education with a "teaching school" at the University of Johannesburg', Education as Change 18(Suppl 1), 107-119. https://doi.org/10.1080/16823206.2013.877357

Green, W., Adendorff, M. \& Mathebula, B., 2012, 'Minding the gap? A national Foundation Phase teacher supply and demand analysis: 2012-2020', South African Journal of Childhood Education (SAJCE) 4(3), 1-23, viewed 21 August 2018, from http://www.sajce.co.za/index.php/sajce/article/view/222

Hall, K., 2017, Child support grants, viewed 27 August 2018, from http://childrencount. uct.ac.za/indicator.php?domain $=2$ \&indicator $=10$

Henning, E., 2014, 'Views of childhood and knowledge of children', South African Journal of Childhood Education (SAJCE) 4(2), n/a. https://doi.org//10.4102/sajce. v4i2.200

Henning, E., Van Rensburg, W. \& Smit, B., 2004, Finding your way in qualitative research, Van Schaik, Johannesburg.

Isaacs, S., Spencer-Smith, G. \& Roberts, N., 2018, Play well and be happy evaluation research brief, LEGO Foundation, Johannesburg, Sesame Workshop.

Landreth, G.L., Ray, D.C. \& Bratton, S.C., 2009, 'Play therapy in elementary schools', Psychology in the Schools 46(3), 281-289. https://doi.org/10.1002/pits.20374

Linden, A., 2018, 'E Cape Grade 1 failure crisis', Dispatch Live, viewed 21 August 2018, from https://www.dispatchlive.co.za/news/2018-03-13-e-cape-grade-1-failurecrisis/

Merriam, S., 1998, Qualitative research and case study application in education, Jossey Bass, San Francisco, CA.

Neha, M. \& Rule, P., 2018, 'Imaginative play and reading development among Grade R learners in KwaZulu-Natal: An ethnographic case study', South African Journal of Childhood Education (SAJCE) 8(1), 1-8.

Ogunyemi, F. \& Ragpot, L., 2015, 'Work and play in early childhood education: Views from Nigeria and South Africa', South African Journal of Childhood Education (SAJCE) 5(3), 1-10. https://doi.org/10.4102/sajce.v5i3.344

Partin, T.C.M., Robertson, R.E., Maggin, D.M., Oliver, R.M. \& Wehby, J.H., 2009, 'Using teacher praise and opportunities to respond to promote appropriate student behavior', Preventing School Failure: Alternative Education for Children and Youth 54(3), 172-178. https://doi.org/10.1080/10459880903493179

Pellegrini, A.D., 2010, The role of play in human development, Oxford University Press, New York.

Pellegrini, A.D., 2009, 'Play: What is it?', in The role of play in human development, Oxford University Press, New York.

Pellegrini, A.D., 2012, 'Play', in Encyclopedia of human behavior, 2nd edn., pp. 126-131, Elserivier, London.

Petker, G. \& Petersen, N., 2014, 'Service learning in Foundation Phase teacher education: Experiential learning opportunities for student teachers', South African Journal of Childhood Education (SAJCE) 4(3), 122-135. https://doi.org/ African Journal of Childho

Piaget, J., 1962, Play, dreams and imitation in childhood, Routledge, London.

Ryan, S. \& Northey-Berg, K., 2014, 'Professional preparation for a pedagogy of play', in The SAGE handbook of play and learning in early childhood, SAGE Publications, Los Angeles, CA.

Takalane Sesame, 2017, Play Well \& Be Happy practitioner's guide, Takalane Sesame, Sesame Workshop and LEGO Foundation, East London.

Talbot, J.P. \& Thornton, L., 2017, A child's right to play: A policy brief for South Africa, A Chance to Play Southern Africa, Johannesburg.

United Nations Children's Fund (UNICEF), 2015, UNICEF procedure for ethical standards in research, evaluation, data collection and analysis, UNICEF, New York, standards in research, evaluation, data collection and analysis, UNICEF, New York, viewed 30 August 2018, from https://www.unicef.org/

Vygotsky L, 1967 'Play and its role in the mental development of the child', Soviet Psychology 5(3), 6-18. https://doi.org/10.2753/RPO1061-040505036

Weisberg, D.S., Zosh, J.M., Hirsch-Pasek, K. \& Golinkoff, R.M., 2013, 'Taking it up: Play language development and the role of adult support', American Journal of Play $6(1), 39-54$, National Museum of Play, New York.

Wood, E., 2009, 'Developing a pedagogy of play', in A. Anning, J. Cullen \& M. Fleer (eds) Early childhood education: Society and culture, pp. 27-38, 2nd edn., SAGE Publications, London.

Zosh, J.M., Hirsh-Pasek, K., Hopkins, E.J., Jensen, H., Liu, C.C., Neal, D. et al., 2018, 'Accessing the inaccessible: Redefining play as a spectrum', Frontiers in Psychology 9, 1-12. https://doi.org/10.3389/fpsyg.2018.01124 